\title{
Normative Data for Calf Muscle Flexibility Tested by Weight Bearing Lunge Test in Age Group of 20-30 Years - Pilot Study
}

\author{
Riddhi Gohil ${ }^{1}$, Prajakta Tilaye ${ }^{2}$ \\ ${ }^{1}$ Intern, K.J Somaiya College of Physiotherapy, Sion, Mumbai-400022 \\ ${ }^{2}$ Assistant Professor, K.J Somaiya College of Physiotherapy, Sion, Mumbai-400022 \\ Corresponding Author: Riddhi Gohil
}

DOI: https://doi.org/10.52403/ijhsr.20220209

\begin{abstract}
Background: Calf muscle is important in the typical gait cycle, jumping, running, and maintaining balance. Tightness limits movement, which can result in injuries or a reduction in task efficiency. Calf muscles flexibility is therefore crucial. No normative range is available for calf muscle flexibility in its functional position. As a result, the goal of this study is to provide normative data using weight bearing lunge test that evaluates tightness in functional position. Results of males and females were compared.

Methods: A cross-sectional pilot study was conducted on 215 people aged 20 to 30 years (males $=100$, females=115). Each participant completed a weight-bearing lunge test after giving consent. For each limb, three trials were given, with the best of the three findings used to analyze the data. Using descriptive analysis, a normative range was produced for both limbs of each gender. The Mann-Whitney test was used to compare the normative ranges.

Results: Females' normative ranges are 12.1-13.4 cm and $12.7-13.9 \mathrm{~cm}$ with a mean and standard deviation of $12.7 \pm 3.3$ and $13.3 \pm 3.4$ for the right and left limb respectively. Males' typical ranges are $13.6 \mathrm{~cm}$ to $14.9 \mathrm{~cm}$ and $13.9 \mathrm{~cm}$ to $14.9 \mathrm{~cm}$ with a mean and standard deviation of $14.2 \pm 3$ and $14.4 \pm$ 2.7 for right and left limb respectively. Male and female normative ranges were found to differ significantly: right $(\mathrm{p}=0.0068)$ and left $(\mathrm{p}=0.0331)$.
\end{abstract}

Conclusion: Our findings give normative data for calf muscle flexibility in both genders, as well as a comparison of these findings.

Key Words: weight bearing lunge test, calf muscle, flexibility, normative range, functional position.

\section{INTRODUCTION}

Calf muscle is one of the most important lower limb muscles. It consists of two muscles; the gastrocnemius muscle forms the superficial part, and the soleus muscle is located underneath.[1]. It plays a major role in ankle range of motion during normal gait cycle especially in stride and push off phase.[2][3]. It is highly important for the athletes as it increases their pace while running, helps them run for longer distance and helps them jump higher.[4][5][6] Ankle movements also help in balancing while walking or running. [7] Therefore calf muscle flexibility is of high importance. Flexibility is the range of motion in a joint or group of joints, or the ability to move joints effectively through a complete range of motion.[8] Tightness restricts the movements which may lead to various injuries or reduce the efficiency of the task. [8] There are various methods to evaluate calf muscle flexibility; it can be evaluated in non-weight bearing supine position or in weight bearing lunge position, the functional position. Weight bearing 
lunge test or knee to wall test is a reliable test to evaluate calf muscle tightness.[9] Simplicity of this test makes it easier for people with non-medical background to perform it accurately as well, for e.g., the PE teachers at school can use this test as a pre-evaluation protocol to avoid injuries, it could be included as pre-evaluator test for non-athlete population who run marathons or take part in annual sports meet etc.

Weight bearing testing has greater advantages over non-weight bearing testing; it closely reflects the load during gait, the force applied to the ankle is independent of the examiner and weight bearing lunge test has higher inter and intra rater reliability.[13] Objective gradings always makes it easier for the evaluator to categorize the individual, it also makes it easier for people to understand where they stand and what levels they need to achieve. Objective values minimize errors and bias. Although being easy to perform and many other benefits there is no normative range available for this test to give appropriate objective values [9][10]. Hence his study aims to give a normative range of calf flexibility in the age group of 20-30 years with objective of forming appropriate normative range and comparing values of males and females.

\section{METHOD}

A cross-sectional pilot study was done across the age group of 20-30 years over a period of 6 months. After taking permission from the ethical committee of K.J Somaiya College of Physiotherapy, participants were recruited through verbal advertisements. Individuals with any form of ankle injury or fracture, knee pain, pregnancy, practising regular yoga or exercises at least thrice a week for more than 3 months were excluded from the study. A total of 215 participants were enrolled which included 100 males and 115 females. An e-consent was taken before including the individual in the study. The participants were briefed about the research study and all their queries were addressed.
They were shown how to perform a weightbearing lunge test, and extra precautions were made considering the covid-19 pandemic. All participants were given 3 chances for each limb and the best outcome was considered for statistical data analysis.

Weight bearing lunge test: It is a very simple, inexpensive test and can be easily conducted in any small clinical setup or area. It requires a wall, measuring tape $(\mathrm{cm})$ or any other tape to stick on the floor. Measuring tape was stuck vertically on the ground from the wall and a vertical line upwards is drawn on the wall ahead from the same point. Participants were instructed to place his/her foot on the tape on the ground in a straight line such that heel, and second toe lie on the same vertical line. The participant then lunges forward to touch his knee to the vertical line drawn on the wall ahead. The leg would be rested on the ground and the participant could use support while lunging forwards. The end position was such that the tested leg's knee touched the wall and the foot on the tape below was completely flat on the ground, with any further movement of the knee forward or foot backward raising the heel off the ground.[10] Participants were given 3 trials to understand the test and get comfortable to obtain accurate measurements and minimize chances of error. Distance between the wall and great toe of the foot $(\mathrm{cm})$ being tested was noted down and was the outcome measure for the study. The best of three trials was considered for the data analysis and the normative values were then established using the whole data set.

The statistical test used to create the normative range is descriptive statistics. For both genders, the mean and standard deviation were computed for each limb. The normative range was created using GraphPad InStat Version 3.10 using the lower- and upper-95 percent confidence limits. The Mann-Whitney test was employed to compare male and female normative data for the right and left limbs, respectively. 


\section{RESULTS}

Analysis of the whole sample lead to the following result: Table 1. represents normative range for females $(\mathrm{n}=115)$, separately for right and left limb. Table 2 . represents normative range for males $(\mathrm{n}=100)$, separately for right and left limb. Comparison of normative values of both the genders were done separately for right and left limb. Mann-Whitney test revealed significant difference between values of males and females; right ( $\mathrm{p}=0.0068$ highly significant $)$ and for left $(p=0.0331$ significant). Mean values were higher for males for both right (mean=14.245) and left $($ mean $=14.39)$ limb, implying that the male normative range is substantially higher than the female normative range. Table 3 . And Table 4. Represent comparative study for right and left limb, respectively.

Table 1.

\begin{tabular}{|l|l|l|l|l|}
\hline Limb & Mean $( \pm$ SD) & Lower 95\% confidence limit & Upper 95\% confidence limit & SEM \\
\hline Right & $12.7( \pm 3.3)$ & 12.1 & 13.4 & 0.3 \\
\hline Left & $13.3( \pm 3.4)$ & 12.7 & 13.9 & 0.3 \\
\hline
\end{tabular}

Table 2.

\begin{tabular}{|l|l|l|l|l|}
\hline Limb & Mean $( \pm$ SD) & Lower 95\% confidence limit & Upper 95\% confidence limit & SEM \\
\hline Right & $14.2( \pm 3.0)$ & 13.6 & 14.9 & 0.3 \\
\hline Left & $14.4( \pm 2.7)$ & 13.9 & 14.9 & 0.3 \\
\hline
\end{tabular}

Table 3.

\begin{tabular}{|l|l|l|ll|}
\hline $\begin{array}{l}\text { Right } \\
\text { limb }\end{array}$ & Mean & $\begin{array}{l}\text { Standard } \\
\text { deviation }\end{array}$ & P value & \\
\hline Females & 12.743 & 3.323 & $\begin{array}{l}0.0068 \\
\text { significant) }\end{array}$ & (very \\
\hline Males & 14.245 & 3.054 & & \\
\hline
\end{tabular}

Table 4.

\begin{tabular}{|l|l|l|l|}
\hline Left limb & Mean & $\begin{array}{l}\text { Standard } \\
\text { deviation }\end{array}$ & P value \\
\hline Females & 13.343 & 3.365 & \multirow{2}{*}{0.0331 (significant) } \\
\hline Males & 14.390 & 2.726 & \\
\hline
\end{tabular}

Table 5.

\begin{tabular}{|l|l|l|}
\multicolumn{2}{c}{} & \multicolumn{3}{c|}{ Table 5. } \\
\hline Gender & Limb & Normal range (cm) \\
\hline \multirow{2}{*}{ Females } & Right & $12.1-13.4$ \\
\cline { 2 - 3 } & Left & $12.7-13.9$ \\
\hline \multirow{2}{*}{ Males } & Right & $13.6-14.9$ \\
\cline { 2 - 3 } & Left & $13.9-14.9$ \\
\hline
\end{tabular}

\section{DISCUSSION}

This study established normative range for calf muscle flexibility using weight bearing lunge test in age group of 20-30 years. Mean and standard deviation were calculated individually for each limb for both the genders. There was a significant difference between normative range for females and males which could be attributed to physiological differences. According to our data set males were more flexible than females, this does not coincide with authors like Olga Delgado Valdivia [11] whose study shows that females are more flexible than males and flexibility decreases with age. One of the reasons behind greater flexor muscle performance among women compared to men could be due to fundamental hormonal variations between the sexes, given that oestrogen levels are higher in women and this produces water retention and a higher percentage of adipose tissue and lower muscle mass, making women anatomically more adept at executing a wider range of joint movements [11]. Anthropometric difference between two sexes could be the reason behind more flexibility in males in the given test position. Anthropometric values were not considered as it was out of the scope of this study.

Differences of $0-3 \mathrm{cms}$ between right and left limb of the participants were noted which is considered normal according to Matthew C. Hoch [10]. Previously weight bearing lunge test was either used as a prognosis measure to compare the effectiveness of the ongoing training program or distance of less than $10 \mathrm{cms}$ was considered as less flexible [9]. According to previous studies, $1 \mathrm{~cm}$ away from the wall is equal to $3.6^{\circ}$ of ankle dorsiflexion.[10]. When we apply this to our data set, we get our ankle dorsiflexion ROM in weight bearing position as follows:

$-15 \mathrm{~cm}=43.2^{\circ}-54^{\circ}$ of ankle dorsiflexion.

Normative range for ankle dorsiflexion in weight bearing position given by Alon Rabin, Zvi Kozol [12] are $50.4 \pm 6.6^{\circ}$ for dominant limb and $56.3 \pm 7.3^{\circ}$ for non-dominant limb. This supports our 
finding as our values lie in the normative range of motion.

This is the first study to establish normative range of WBLT to evaluate the calf muscle flexibility in a wide range of age group of 20-30 years. It has numerous clinical applications as a set of objective values always gives more strength to the diagnosis. These values make it easier for the clinician to evaluate the individual appropriately in the weight bearing position. Since no additional equipment is necessary, this test can be incorporated in a preevaluation routine for many sports such as football, volleyball, cricket, and others to determine the risk of injury. It will be highly beneficial during functional training phase of rehabilitation.

Anthropometric data and lower limb dominance were not considered, which are the study's shortcomings. This research can be advanced by involving a wide population to validate the findings. An analysis of anthropometric parameters and lower limb dominance may shed more insight on the male-female value disparity. This test can be used on a wide range of people to determine age-specific objective values, such as the adolescence normative range, 30-40 years old, and so forth. We can also divide tightness into three categories: mild, moderate, and severe.

\section{CONCLUSION}

We have provided normative range for calf muscle flexibility using weight bearing lunge test for males and females of age group 20-30 years. (table 5.) Flexibility is generally more in females than males, but our study suggests otherwise.

\section{ACKNOWLEDGEMENT}

I, Riddhi Rajesh Gohil, Intern (B. P. Th), Batch 2016-17 would like to thank Dr. Shweta Manwadkar, Principal and Dr. Prajakta Tilaye, Assistant Professor, K. J. Somaiya College of Physiotherapy for their sincere efforts and guidance. I would also like to extend my gratitude to all my subjects for their invaluable contribution to my research project.

\section{Conflict of Interest: None}

\section{Source of Funding: None}

\section{Ethical Approval: Approved}

\section{REFERENCES}

1. B D Chaurasia's. Human Anatomy Volume 2. Seventh Edition, CBS Publishers \& Distributors- New Delhi, 2016.

2. Ericson MO, Nisell R, Ekholm J. Quantified electromyography of lower-limb muscles during level walking. Scand J Rehabil Med. 1986;18(4):159-63.

3. Brandell BR. Functional roles of the calf and vastus muscles in locomotion. Am $\mathrm{J}$ Phys Med. 1977 Apr;56(2):59-74.

4. Jenna Cartwright. The Importance of Calf Strength and the BEST Calf Strength Exercises. Sports and spinal physiotherapy.16 August 2019.

5. Tsuji K, Ishida H, Oba K, Ueki T, Fujihashi Y. Activity of lower limb muscles during treadmill running at different velocities. J Phys Ther Sci. 2015;27(2):353-356.

6. Simonsen EB, Alkjær T, Raffalt PC. Reflex response and control of the human soleus and gastrocnemius muscles during walking and running at increasing velocity. Exp Brain Res. 2012 Jun;219(2):163-74.

7. JeonHyeong Lee, JongSung Chang - The Effect of Calf Stiffness on Gait, Foot Pressure and Balance in Adults. J Kor Phys Ther 2019;31(6):346-350.

8. Jennifer R. Scott. Health and Fitness Benefits of Flexibility Training. Verywellfit. Updated on May 14, 2021 https://www.verywellfit.com/flexibilitydefinition-and-examples-3496108

9. Marie Mann. Two tests you can do to check if your calves are tight and stretches to fix lack Of flexibility. Mpower-fitness, 2014. https://mpower-

fitness.co.uk/WP/wpcontent/uploads/2014/0 3/Calf_health_check_doc.pdf

10. Matthew C. Hoch, Patrick O. McKeon. Normative range of weight-bearing lunge test performance asymmetry in healthy adults. Manual Therapy 16 (2011) 516e519

11. Olga Delgado Valdivia, Maria Angustias Martin Canadá, Felix Zurita Ortega, Jose 
Riddhi Gohil et.al. Normative data for calf muscle flexibility tested by weight bearing lunge test in age group of 20-30 years- pilot study.

Joaquin Antequera Rodriguez and Manuel Fernandaze Sanchez. Changes in flexibility according to gender and educational stage. Apunts Med Esport. 2009;161:10-7.

12. Rabin A, Kozol Z, Spitzer E, Finestone. Weight-bearing ankle dorsiflexion range of motion-can side-to-side symmetry be assumed? AS J Athl Train. 2015;50(1):3035.

13. Bennell KL, Talbot RC, Wajswelner $\mathrm{H}$, Techovanich W, Kelly DH. Intra-rater and inter-rater reliability of a weight-bearing lunge measure of ankle dorsiflexion. Hall AJ. Australian Journal of Physiotherapy 1998;44(3):175-180.

How to cite this article: Gohil R, Tilaye P. Normative data for calf muscle flexibility tested by weight bearing lunge test in age group of 2030 years- pilot study. Int J Health Sci Res. 2022; 12(2): 71-75. DOI: https://doi.org/10.52403 /ijhsr.20220209 